\title{
Associations between Diet Quality, Weight Status and Academic Performance in Senior High-School Students in Tehran
}

\author{
Mohammad Reza Mazandaranian ${ }^{1}$, Nasrin Omidvar*² ${ }^{2}$ Hassan Eini-Zeinab ${ }^{3}$, Azam Doustmohammadian ${ }^{4}$, Marziye Ashoori ${ }^{3}$, Behnaz \\ Abdar-Esfahni ${ }^{3}$, Omid Hosseini-Mousavi ${ }^{3}$ \\ 1- Master of Nutrition sciences Department of Community Nutrition, Faculty of Nutrition Sciences and Food Technology, National Nutrition, and Food \\ Technology Research Institute, Shahid Beheshti University of Medical Sciences and Health Services, Tehran, Iran \\ 2- Department of Community Nutrition, Faculty of Nutrition Sciences and Food Technology, National Nutrition, and Food Technology Research \\ Institute, Shahid Beheshti University of Medical Sciences and Health Services, Tehran, Iran \\ 3- Department of Community Nutrition, Faculty of Nutrition Sciences and Food Technology, National Nutrition, and Food Technology Research \\ Institute, Shahid Beheshti University of Medical Sciences and Health Services, Tehran, Iran \\ 4- Gastrointestinal and Liver Diseases Research Center, Iran University of Medical Sciences, Tehran, Iran
}

Accepted: December 2020

\section{A B S T R A C T}

Background and Objectives: To study associations in diet quality academic performance and weight status in urban adolescent high-school students.

Materials and Methods: This study was a cross-sectional study in high schools in Tehran, Iran. A total of 629 students (317 boys and 309 girls), aging 17-19 years, from 49 high schools participated in the study. Dietary intake was measured using two 24-h recalls. Diet quality was measured using Healthy Eating Index-2015. Academic performance was assessed by evaluating scores achieved in national exams at the end of high-school junior year. Standard anthropometric measurements were used. Linear and multinomial regressions were used to assess the associations between weight status, diet quality and academic performance.

Results: Student's scores in grammar and literature were significantly associated to diet quality $(p<0.05)$. After adjusting for sex and other socioeconomic confounders, the association was non-significant. Significant differences were seen in weight status between boys and girls; however, such differences were not based on the prosperity levels in weight statuses. The overall frequency of overweight was nearly $24 \%$, while obesity was twice in boys (nearly $26 \%$ ), compared to girls.

Conclusions: Findings verify needs of policies to improve student diet quality, leading to better health and educational achievements. Further studies are needed to investigate associations between diet quality and academic performance.

Keywords: Diet quality, Weight status, Academic performance, Adolescents

\section{Introduction}

Children academic performance affects their future educational achievements and health; therefore, academic performance is a major public health concern (1). Students with poor academic performances are more prone to obesity, unemployment and low socioeconomic status in adulthood (2). Various factors are associated to academic performance, including gender, ethnicity, nutrition, weight status, stress level and socioeconomic status $(3,4)$. Nutrition as the most modifiable environmental factor that affects weight and academic performance has been focused in most recent studies (5). It has been shown that healthier diets consisting of adequate nutrients, more fruits, vegetables and whole grains and less processed foods are associated to better academic achievements $(2,5,6)$. Studies have assessed associations between diet quality and academic performance (7-9). In a study in Chili, students with unhealthy diets were more likely to have poor academic performances (7). Florence et al. study (9) showed that a better quality of diets was associated to better reading skills. Obesity as a potential factor associating with academic performance is presently a major concern in Iran. Based on the latest national survey, prevalence of obesity in adolescents was nearly $12 \%$ (10). A few studies have assessed effects of diet quality and 
weight status on adolescent academic performance with no clear associations (11-13). Considering that student poor diet and obesity can play roles in their academic performance and due to the data gap in this area, the aim of the current study was to assess associations between diet quality, weight status and academic performance in senior high-school students in City of Tehran, Iran.

\section{Materials and Methods}

\section{Study design and sampling}

This cross-sectional study was carried out in senior high-school students in City of Tehran, Iran. The target population included 51,650 students; of whom, 629 students (317 boys and 309 girls) participated in the study. Data were collected from November 2017 to April 2018. A multistage systematic cluster sampling approach was used in three stages to classify districts, schools, classes and children. Tehran General Office of Education classifies its 19 educational districts into three socioeconomic levels of affluent, semi-affluent and deprived. In the first stage, nine districts (three from each of the three socioeconomic areas) were selected by weighting districts based on their student population density. In each district, public and private schools were selected based on their student populations. High-school seniors (aged 17-18 years) were randomly selected from each school in the third stage. A team of nine trained nutritionists collected data. A supervisor ensured consistency of the work during data collection. Participants received full verbal and written explanations of the study purpose before they signed the consent forms. Data were collected in the schools. The National Nutrition and Food Technology Research Institute Ethical Committee approved the study protocol (ethical code: IR.SBMU.nnftri.Rec.1396.166, October 16, 2018).

\section{Data collection}

Dietary intakes were assessed using two 24-h recalls, including one at weekday and one at weekend, from each student by trained nutritionists through in-person interviews (10). The United States Department of Agriculture (USDA) database and Nutrition IV Software were used to assess the student macro and micronutrient intake. Healthy Eating Index (HEI)-2015 was used to assess diet quality. Dietary intake nutrients were based on a density basis (per 1,000 kcal), except for fatty acids and added sugars. The nine components that assessed adequacy of the diets included whole fruits, total fruits, total greens and beans, vegetables, whole grains, dairies, total protein foods, seafood, plant proteins and fatty acids. Refined grains, sodium, added sugars and saturated fats were considered as moderation components. Only after meeting standards for the total protein foods, legumes were counted in vegetables and greens and beans groups. The total HEI2015 score ranged 0-100 with higher score showed better adherence to the dietary guidelines (14). Academic performance was assessed using student grades from the national final exams at the end of the high-school senior year. These exams covered all textbooks taught during high-school senior year. Student grade point average (GPA), as well as grades in mathematics and languages (grammar and literature), were used to assess the academic performance. Range of scores for every exam was 0-20 and the minimum score for passing courses was 10 .

Student anthropometric measurements, standing height (cm) and weight $(\mathrm{kg})$ were measured twice. Two digital scales were used to measure weight to the exact $0.1 \mathrm{~kg}$. Scales were calibrated using predefined weight before starting weight measurements and after every 20 samples. Standing height was measured to the nearest $0.1 \mathrm{~cm}$ using tape measure. The tape measure was set vertically against the wall, $50 \mathrm{~cm}$ above the floor. A big flat square was used to set a right angle with the wall to ensure the height measurement accuracy. Students were asked to remove shoes and bulky clothes before measurements. Body mass index (BMI) was calculated as weight $(\mathrm{kg})$ divided by the square of height $(\mathrm{m})$. The BMI for age Z-score was calculated based on WHO Standards for Children of 5-19 years old, which categorized them into severe thinness ( $Z$ score less than $-3 \mathrm{SD}$ ), thinness (Z-score from $-3 \mathrm{SD}$ to -2 $\mathrm{SD}$ ), normal (Z-score from $-2 \mathrm{SD}$ to $1 \mathrm{SD}$ ), overweight ( $\mathrm{Z}$ score from $1 \mathrm{SD}$ to $2 \mathrm{SD})$ and obese (Z-score more than 2 $\mathrm{SD})$ children (15).

\section{Covariates}

Covariates included age, birth order (first or $\leq 2$ ), family size $(<4,4$ or $>4)$, father's age tertile (T1: age 35-47 years; T2: age 47-53 years; or T3: > 53 years), mother's age tertile (T1: age 30-40 years; T2: age 40-45 years; or T3: > 45 years), parents education (illiterate or five years of school, under diploma, diploma, associate degree or higher), father's job (worker, employee, self-employed, high-income job or retired), mother's job (housewife, working outside the home), house ownership (owner, tenant, mortgage or others), Children's physical activities were measured using locally validated version of the Child and Adolescent International Physical Activity Questionnaire (16) through face-to-face interviews with the children.

\section{Statistical analysis}

Normality of distribution was assessed using Kolmogorov-Smirnov test. Data were presented as mean and standard deviation (SD) for continuous variables and frequency for categorical variables. One-way ANOVA was used to assess differences between continuous variables in more than two groups. Associations of diet quality and weight status with academic performance were analyzed using linear regression test. Three models were used for linear regression, including 1) without imputing 
controls; controlling for 2) sex; and 3) sex, major, school district, parents' education, parents' age, parents' job position, residence type, house area, house room number, school type and physical activity. In general, $p$-values lower than 0.05 were considered as statistically significant. All statistical analyses were carried out using Statistical Package for the Social Sciences Software v.25, (SPSS, Chicago, IL, USA).

\section{Results}

\section{Characteristics of the study participants}

After exclusion of over and underestimated cases based on total energy intakes (17), results from 557 students (304 boys and 253 girls) were finally analyzed. General characteristics of the participants are presented in Table 1.
Based on the WHO BMI-for-age Z-scores, $16 \%$ of the participants were obese and obesity was more frequent in boys, compared to girls (22\% compared to $8.5 \%$ ). Furthermore, $50 \%$ of the boys and $67 \%$ of the girls had normal weights (Table 1). Tables 2 and 3 show the participants' demographic and socioeconomic characteristics based on the area of residence level of prosperity. Compared to lower prosperous areas, parents were older in affluent areas ( $p=0.034$ for father's age, $p=$ 0.005 for mother's age) who had higher education levels ( $p$ $<0.0001)$ and students attended mostly private schools rather than public schools $(p<0.0001)$. In affluent areas, fathers had better jobs as well $(p<0.0001)$ and mothers were more likely to work outside the homes $(p=0.02)$, compared to the two other levels.

Table 1 . Diet quality, weight and academic performance in Iranian students

\begin{tabular}{lccc}
\hline Characteristics & all & Boys & girls \\
\hline BMI Z score, $\mathrm{n}(\%)$ & & & $5(2.0)$ \\
Thin & $11(2.0)$ & $6(2.0)$ & $166(67.2)$ \\
Normal & $318(58.2)$ & $152(50.8)$ & $55(22.3)$ \\
Overweight & $129(23.6)$ & $74(24.7)$ & $21(8.5)$ \\
Obese & $88(16.1)$ & $67(22.4)$ & \\
BMI, Kg/m ${ }^{2}$ (mean \pm SD) & & & $23.41 \pm 4.47$ \\
& $24.39 \pm 5.03$ & $25.20 \pm 5.32$ & \\
Academic performance score $(0-20)($ mean \pm SD) & & & $12.89 \pm 3.99$ \\
Mathematics & $12.03 \pm 4.31$ & & $16.49 \pm 2.38$ \\
Grammar & $15.25 \pm 2.90$ & $11.32 \pm 4.44$ & $16.38 \pm 3.08$ \\
Literature & $15.07 \pm 3.71$ & $14.22 \pm 2.90$ & $15.0 \pm 2.59$ \\
Gpa & $13.96 \pm 3.07$ & $13.99 \pm 3.84$ & $13.10 \pm 3.17$ \\
Major, n(\%) & & & $80(31.6)$ \\
Mathematical Sciences & & & $101(39.9)$ \\
Natural sciences & $248(44.5)$ & $168(55.3)$ & $72(28.5)$ \\
Humanities & $186(33.4)$ & $85(28.0)$ & $46.99 \pm 10.32$ \\
HEI- 2015 (mean \pm SD) & $123(22.1)$ & $51(16.8)$ & $44.16 \pm 9.98$ \\
\hline
\end{tabular}

BMI indicates Body mass index

based on the WHO BMI z score for age.

${ }^{\mathrm{b}}$ based on national exams conducted at the end of high school junior year.

Table 2 . Demographic characteristics of the Iranian students by level of prosperity of residence areas

\begin{tabular}{|c|c|c|c|c|c|}
\hline Classifications & All n(\%) & Deprived $\mathrm{n}(\%)$ & Semi affluent $\mathrm{n}(\%)$ & Affluent n(\%) & $\overline{P \text { value }}$ \\
\hline \multicolumn{6}{|l|}{ Birth order } \\
\hline$<2$ & $286(49.8)$ & $72(55.8)$ & $62(45.3)$ & $142(49.3)$ & 0.22 \\
\hline$\geq 2$ & $278(50.2)$ & $57(44.2)$ & $75(54.7)$ & $146(50.7)$ & \\
\hline \multicolumn{6}{|c|}{ Fathers age tertile, y } \\
\hline $35-47$ & $246(44.8)$ & $69(55.2)$ & $61(45.2)$ & $116(40.1)$ & 0.034 \\
\hline $47-53$ & 197(35.9) & $31(24.8)$ & $50(37.0)$ & $116(40.1)$ & \\
\hline$>53$ & $106(19.3)$ & $25(20.0)$ & $24(17.8)$ & $57(19.7)$ & \\
\hline \multicolumn{6}{|c|}{ Mothers age tertile, y } \\
\hline $30-40$ & $193(34.9)$ & $61(48.0)$ & $47(34.6)$ & $85(29.3)$ & 0.005 \\
\hline $40-45$ & 194(35.1) & $33(26.0)$ & $52(38.2)$ & $109(37.6)$ & \\
\hline$>45$ & $166(30.0)$ & $33(26.0)$ & $37(27.2)$ & $96(33.1)$ & \\
\hline
\end{tabular}

\footnotetext{
*Significant at $\mathrm{P}<.05$ for chi-square tests of independence.
} 
Mohammad Reza Mazandaranian, et al: Diet, weight status and academic performance

Table 3 . Socioeconomic characteristics of the Iranian students by level of prosperity of residence areas

\begin{tabular}{|c|c|c|c|c|c|}
\hline & all & deprived & Semi-affluent & affluent & $\mathrm{P}$-value ${ }^{*}$ \\
\hline $\begin{array}{l}\text { School type } \\
\text { public } \\
\text { private }\end{array}$ & $\begin{array}{l}392(70.4) \\
165(29.6)\end{array}$ & $\begin{array}{c}106(82.2) \\
23(17.8)\end{array}$ & $\begin{array}{c}115(83.9) \\
22(16.1)\end{array}$ & $\begin{array}{l}171(58.8) \\
120(41.2)\end{array}$ & $<0.0001$ \\
\hline $\begin{array}{l}\text { Family size } \\
<4 \\
4 \\
>4\end{array}$ & $\begin{array}{l}107(19.2) \\
300(53.9) \\
150(26.9)\end{array}$ & $\begin{array}{l}21(16.3) \\
69(53.5) \\
39(30.2)\end{array}$ & $\begin{array}{l}22(16.1) \\
70(51.1) \\
45(32.8)\end{array}$ & $\begin{array}{c}64(22.0) \\
161(55.3) \\
66(22.7)\end{array}$ & 0.134 \\
\hline $\begin{array}{l}\text { Fathers education } \\
\text { Illiterate or } 5 \text { y } \\
\text { under diploma } \\
\text { diploma } \\
\text { Associate's degree or higher }\end{array}$ & $\begin{array}{c}9(1.6) \\
112(20.1) \\
257(46 . .2) \\
178(32.0)\end{array}$ & $\begin{array}{c}5(3.9) \\
51(39.5) \\
52(40.3) \\
21(16.3)\end{array}$ & $\begin{array}{c}0(0.0) \\
34(24.8) \\
74(54.0) \\
29(21.2)\end{array}$ & $\begin{array}{c}4(1.4) \\
27(9.3) \\
131(45.2) \\
128(44.1)\end{array}$ & $<0.0001$ \\
\hline $\begin{array}{l}\text { Mother's education } \\
\text { Illiterate or } 5 \mathrm{y} \\
\text { under diploma } \\
\text { diploma } \\
\text { Associate's degree or higher }\end{array}$ & $\begin{array}{c}12(2.2) \\
122(21.9) \\
281(50.4) \\
142(25.5)\end{array}$ & $\begin{array}{c}6(4.7) \\
54(41.9) \\
57(44.2) \\
12(9.3)\end{array}$ & $\begin{array}{c}2(1.5) \\
35(25.5) \\
76(55.5) \\
24(17.5)\end{array}$ & $\begin{array}{c}4(1.4) \\
33(11.3) \\
148(50.9) \\
106(36.4)\end{array}$ & $<0.0001$ \\
\hline $\begin{array}{l}\text { Father's job position } \\
\text { worker } \\
\text { employee } \\
\text { Self-employed } \\
\text { High-income jobs } \\
\text { Retired }\end{array}$ & $\begin{array}{l}70(12.6) \\
140(25.1) \\
202(36.3) \\
53(9.5) \\
92(16.5)\end{array}$ & $\begin{array}{c}35(27.1) \\
24(18.6) \\
42(32.6) \\
4(3.1) \\
24(18.7)\end{array}$ & $\begin{array}{l}18(13.1) \\
25(18.2) \\
58(42.3) \\
12(8.8) \\
25(17.5)\end{array}$ & $\begin{array}{c}17(5.8) \\
91(31.3) \\
102(35.1) \\
37(12.7) \\
44(14.1)\end{array}$ & $<0.0001$ \\
\hline $\begin{array}{l}\text { Mother's employment } \\
\text { Working } \\
\text { Housewife }\end{array}$ & $\begin{array}{c}90(16.2) \\
467(83.8)\end{array}$ & $\begin{array}{c}12(9.3) \\
117(90.7)\end{array}$ & $\begin{array}{c}20(14.6) \\
117(85.4)\end{array}$ & $\begin{array}{c}58(19.9) \\
233(80.1)\end{array}$ & 0.02 \\
\hline $\begin{array}{l}\text { House ownership status } \\
\text { owner } \\
\text { Tenant, mortgage, or others }\end{array}$ & $\begin{array}{l}390(70.0) \\
167(30.0)\end{array}$ & $\begin{array}{l}84(65.1) \\
45(34.9)\end{array}$ & $\begin{array}{c}107(78.1) \\
30(21.9)\end{array}$ & $\begin{array}{c}199(68.4) \\
92(31.6)\end{array}$ & 0.047 \\
\hline
\end{tabular}

*Significant at $\mathrm{P}<.05$ for chi-square tests of independence.

\section{Associations between weight status and academic performance}

Multiple linear regressions were used to estimate associations between the students' weight status and their academic performance (Table 4). In raw regression, girls' weight status was reversely associated to their grades in math, literature and grammar as well as their GPA; however, associations were significant only between literature score and weight status, comparing normalweight students to overweight ones. In boys, being obese was positively associated to higher grades in math, compared to normal-weight students. Overweight boys had higher grades in all subjects, except math, compared to normal-weight students. However, results did not change after adjusting for confounders.

\section{Associations between diet quality and academic performance}

Multiple linear regressions were used to estimate associations between diet quality (based on HEI-2015) and academic performance (based on scores achieved in national exams) (Table 5). The mean score of HEI was 45.57 in students and the mean score of girls was higher than boys (46 and 44, respectively). Student's scores in grammar and literature were significantly associated to diet quality score $(p<0.05)$. After adjusting for confounders, this association was still significant. The adjusted model is shown in Table 5, indicating that associations were favorable for all the exam grades and GPA with no significance. 


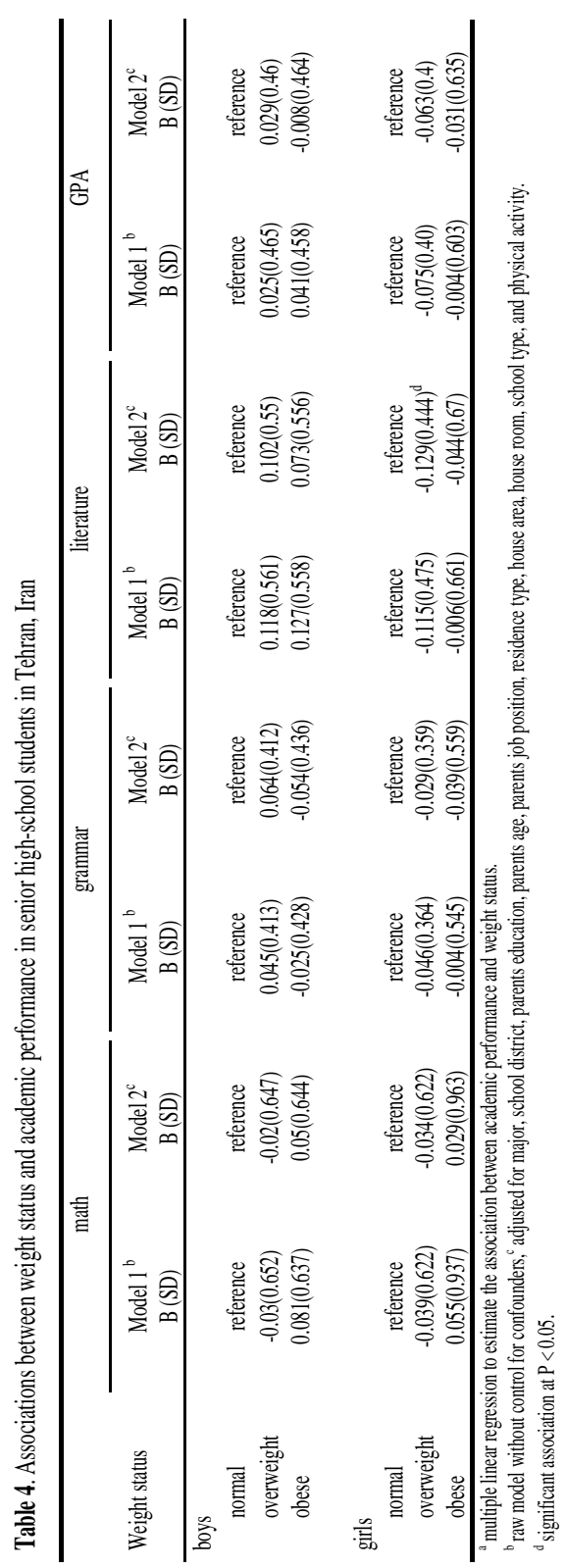

Table 5. Associations between diet quality and academic performance in Iranian students

\begin{tabular}{lcc}
\hline & \multicolumn{2}{c}{ HEI_2015 } \\
\hline Academic performance & Model 1 $^{\mathrm{b}}$ & Model 2 \\
Math & $0.028(0.018)$ & $0.011(0.018)$ \\
Grammar & $0.118(0.012)^{*}$ & $0.095(0.012)^{*}$ \\
Literature & $0.087(0.016)^{*}$ & $0.069(0.015)^{*}$ \\
GPA & $0.067(0.013)$ & $0.044(0.013)$ \\
\hline
\end{tabular}

HEI: Healthy Eating Index.

${ }^{a}$ multiple linear regression to estimate the association between academic performance and diet quality

${ }^{\mathrm{b}}$ raw model without control for confounders.

${ }^{c}$ adjusted for sex, major, school district, parents education, parents age, parents job position, residence type, house area, house room, school type, and physical activity and BMI for age.

" significant association.

\section{Discussion}

Results of this study showed that diet quality was not strongly associated to academic performance in high school leavers in Tehran. However, diet quality was significantly associated to grammar and literature performances in the raw model and even after adjusting for confounders. Weak reverse associations were seen between weight status and academic performance, specifically in girls. Several studies have reported significant associations between diet quality and academic performance in adolescents (2-5). A study by Tayebi et al. on 16 and 17-year-old students showed that students with healthier dietary habits higher consumed fruits and zinc and iron supplements and less junk foods and were more likely to include better academic performance (6). Another study in Canada showed that students in the top quartile of diet quality were more likely to include better academic performance (9). A study on Chilean students demonstrated that students with healthy diets had better academic performances, compared to those with unhealthy diets (7).

It can be concluded that nutrients that affect brain function are strongly affected by the diets (18). Evidence have shown that healthy diets in the early years of life include major roles in development of the frontal lobe of brain that performs conscious thinking processes. Supplementation with iron, iodine, omega-3 fatty acids and vitamin B-12 improves the brain development. Studies have shown that amino acids such as tryptophan in dairy products are precursors of serotonin (15). It has been suggested that the food quantity and quality are linked to academic performance (19). More consumption of saturated fats and added sugar can lower the mind activity by increasing oxidative stress and lowering neutrophilic factors in the brain (20). Moreover, flavonoid and nonflavonoid polyphenols in fruits and vegetables include positive effects on memory and brain activity, possibly due to antioxidant and anti-inflammatory effects of the polyphenols which can result in facilitation of the neuromessaging in the brain (21). The academic performance was affected by the socioeconomic status and this might include adjustments on relationships of diet quality and academic performance. Factors, including sociodemographic elements, affected diets and thus associations between academic performance and diets did not occur independently and were affected by various factors (13).

A study by Kristjansson et al. showed strong associations between weight status and academic performance in teenage students (11). Beltran-Valls et al. in a study on Spanish students showed that students with better weight statuses (normal weight statuses) were more successful in math and language and had better GPAs (12). In the current study, weak relationships between weight status and academic performance might be due to sedentary 
lifestyles in students in the senior year because of the high loads of studies. Associations between weight status and academic performance could be explained from physiological and psychological views (12). Psychologically, students with poorer weight statuses had lower confidence and mental performance and hence were more likely to include poorer academic performances (22). From the physiological views, hormones and neurotransmitters secreted from adipocytes and digestive systems such as adiponectin and inflammatory cytokines were associated to learning and memory functions at younger ages as well as academic performances (23). Leptin includes effects on memory sections of the brain such as the cortex and hippocampus (24). Ghrelin, a hunger hormone secreted from the digestive system, can increase the brain long-term memory capacity (25). The current study limitations included 1) the cross-sectional type of study made it impossible to establish cause-andeffect relationships between the variables. Moreover, this limited possibility of observing metabolic variations might occur by diet quality and include roles in weight status. Possibility of bias caused by the use of tape measures to calculate heights was another limitation. In contrast, the study strength included collecting of confounder variables such as socioeconomic variables. The current study was the first study to investigate associations between diet quality and academic performance in adolescents in Iran.

\section{Conclusion}

In conclusion, findings of this study have verified needs of policies to improve student diet quality, leading to better health and educational achievements. Results have suggested that nutrition and educational programs are needed to teach students more healthy diets and lifestyles. Further studies are necessary to investigate associations between diet quality and academic performance.

\section{Acknowledgement}

This study was funded by the National Nutrition and Food Technology Research Institute, Faculty of Nutrition Science and Food Technology, Shahid Beheshti University of Medical Science, as an MSc thesis (Grant No. 1396.166). The authors would like to thank the Education Department of the university and all the students and teachers who participated in the study.

MR.M, M.A. and B.A-B participated in data collection. MR.M and H.E-Z carried out data analysis; H.E-Z supervised statistical analysis; MR.M, N.O and A.D supervised manuscript preparation.

\section{Financial disclosure}

The authors declared no financial interest.

\section{References}

1. Rampersaud GC, Pereira MA, Girard BL, Adams J, Metzl JD. Breakfast habits, nutritional status, body weight, and academic performance in children and adolescents. Journal of the american dietetic association. 2005;105(5):743-60.

2. Otaegui-Arrazola A, Amiano P, Elbusto A, Urdaneta E, Martinez-Lage P. Diet, cognition, and Alzheimer's disease: food for thought. Eur J Nutr. 2014;53(1):1-23.

3. Benton D. The influence of children's diet on their cognition and behavior. Eur J Nutr. 2008;47 Suppl 3:25-37.

4. Kim SY, Sim S, Park B, Kong IG, Kim JH, Choi HG. Dietary Habits Are Associated With School Performance in Adolescents. Medicine (Baltimore). 2016;95(12):e3096.

5. Burrows T, Goldman S, Pursey K, Lim R. Is there an association between dietary intake and academic achievement: a systematic review. J Hum Nutr Diet. 2017;30(2):117-40.

6. Tayebi S, Pourabbasi A, Shirvani ME. The effects of dietary habits on Iranian students' school performance, a pilot crosssectional study. J Pak Med Assoc. 2014;64(1):20-3.

7. Correa-Burrows P, Burrows R, Blanco E, Reyes M, Gahagan S. Nutritional quality of diet and academic performance in Chilean students. Bull World Health Organ. 2016;94(3):18592.

8. Esteban-Cornejo I, Izquierdo-Gomez R, Gomez-Martinez S, Padilla-Moledo C, Castro-Pinero J, Marcos A, et al. Adherence to the Mediterranean diet and academic performance in youth: the UP\&DOWN study. Eur $\mathbf{J}$ Nutr. 2016;55(3):1133-40.

9. Florence MD, Asbridge M, Veugelers PJ. Diet quality and academic performance. J Sch Health. 2008;78(4):209-15; quiz $39-41$.

10. Mirmiran P, Azadbakht L, Azizi F. Dietary quality-adherence to the dietary guidelines in Tehranian adolescents: Tehran Lipid and Glucose Study. Int J Vitam Nutr Res. 2005;75(3):195-200.

11. Kristjansson AL, Sigfusdottir ID, Allegrante JP. Health behavior and academic achievement among adolescents: the relative contribution of dietary habits, physical activity, body mass index, and self-esteem. Health Educ Behav. 2010;37(1):51-64.

12. Beltran-Valls MR, Adelantado-Renau M, Castro-Pinero J, Sanchez-Lopez M, Moliner-Urdiales D. Cardiorespiratory fitness and academic performance association is mediated by weight status in adolescents: DADOS study. Eur J Pediatr. 2018;177(7):1037-43.

13. Faught EL, Ekwaru JP, Gleddie D, Storey KE, Asbridge M, Veugelers PJ. The combined impact of diet, physical activity, sleep and screen time on academic achievement: a prospective study of elementary school students in Nova Scotia, Canada. Int J Behav Nutr Phys Act. 2017;14(1):29.

14. Reedy J, Lerman JL, Krebs-Smith SM, Kirkpatrick SI, Pannucci TE, Wilson MM, et al. Evaluation of the Healthy Eating Index-2015. J Acad Nutr Diet. 2018;118(9):1622-33.

15. Nyaradi A, Li J, Foster JK, Hickling S, Jacques A, O'Sullivan TA, et al. Good-quality diet in the early years may have a positive effect on academic achievement. Acta Paediatr. 2016;105(5):e209-18. 
16. Kelishadi R, Qorbani M, Motlagh ME, Heshmat R, Ardalan G, Bahreynian M. Association of eating frequency with anthropometric indices and blood pressure in children and adolescents: the CASPIAN-IV Study. J Pediatr (Rio J). 2016;92(2):156-67.

17. McCrory MA, McCrory MA, Hajduk CL, Roberts SB. Procedures for screening out inaccurate reports of dietary energy intake. Public Health Nutr. 2002;5(6a):873-82.

18. Pearce K, Golley R, Lewis L, Cassidy L, Olds T, Maher C. The Apples of Academic Performance: Associations Between Dietary Patterns and Academic Performance in Australian Children. J Sch Health. 2018;88(6):444-52.

19. Molteni R, Barnard RJ, Ying Z, Roberts CK, Gomez-Pinilla F. A high-fat, refined sugar diet reduces hippocampal brainderived neurotrophic factor, neuronal plasticity, and learning. Neuroscience. 2002;112(4):803-14.

20. Wu A, Ying Z, Gomez-Pinilla F. The interplay between oxidative stress and brain-derived neurotrophic factor modulates the outcome of a saturated fat diet on synaptic plasticity and cognition. Eur J Neurosci. 2004;19(7):1699707.
21. Adelantado-Renau M, Beltran-Valls MR. The influence of adherence to the Mediterranean diet on academic performance is mediated by sleep quality in adolescents. 2019;108(2):33946.

22. Kenney EL, Redman MT, Criss S, Sonneville KR, Austin SB. Are K-12 school environments harming students with obesity? A qualitative study of classroom teachers. Eat Weight Disord. 2017;22(1):141-52

23. Miller AL, Lee HJ, Lumeng JC. Obesity-associated biomarkers and executive function in children. Pediatr Res. 2015;77(1-2):143-7.

24. Morrison CD. Leptin signaling in brain: A link between nutrition and cognition? Biochim Biophys Acta. 2009;1792(5):401-8

25. Carlini VP, Ghersi M, Schioth HB, de Barioglio SR. Ghrelin and memory: differential effects on acquisition and retrieval. Peptides. 2010;31(6):1190-3. 